\title{
INTRAOCULAR TENSION IN ASSOCIATION WITH SUCCINYLCHOLINE AND ENDOTRACHEAL INTUBATION: A PRELIMINARY REPORT
}

\author{
J. E. Wynands, M.D., and D. E. Croweli, M.D.
}

IN 1953, Hoffman and Halzer reported the effects of ether anresthesia and pentothal-nitrous oxide anaesthesia on intraocular tension. Since that time a good deal of interest has been shown in this field and in particular on the effect of the muscle relaxant, succinylcholine, on intraocular tension. Iincoff showed in animals that a step-wise dosage of succinylcholine produced proportional increases in intrapcular pressure up to a maximum of 14 to $18 \mathrm{~mm}$. Hg. Striate muscle tension was recorded and, as a control, succinylcholine was administered to produce 90 per cent paralysis of the gastrocnemius muscle. At this dosage succinylcholine produced the above-mentioned ocular results. Lincoff concluded that extrabocular muscle shows a higher threshold to the effect of succinylcholine than does skeletal muscle and that the reaction to succinylcholine appears as a sustained contracture rather than as relaxation. They also concluded that the extraocular myoneural junction as opposed to that in skeletal muscle is not blocked by succinylcholine. In 1957, the above results were supported by the findings of Macri and Grimes and later in the same year by those of Dillon who carried out work on cat extraocular muscle in vitro.

On the basis of the above reports, we felt that the methods of investigation were incomplete in so far as it is reasonable to assume that, since the musclenerve ratio is $1: 1$ in extraocular muscle compared to $100: 1$ in skeletal múscle, a higher concentration of circulating succinylcholine will be required to achieve in extraocular muscle the same degree of relaxation produced in skeletal muscle. Therefore, when the gastrocnemius muscle is 80 per cent paralysed, the extraocular muscle should, theoretically, be paralysed to a far lesser degree.

As contraction of extraocular muscle increases intraocular tension, complete relaxation of extraocular muscle should result in lowered ocular tensions. This lowering of tension would take place if extraocular muscle responded to succinylcholine as does striate muscle: that is, there would be a period of fasiculation, which, when maximal, would be accompanied by a maximal rise in ocular tension that subsequently would fall to normal as the muscle became paralysed.

On the above hypothesis, an investigation was carried out using succinylcholine in association with light pentothal-nitrous oxide anaesthesia so that ocular tension variations might be studied via tonometry. Succinylcholine was employed under three different conditions and the resulting changes in intraocular tension wete noted.

Series $I$. The effect of a single intubating dose of succinylcholine was measured, the time for return to normal being noted.

Series II. A 0.1 per cent succinylcholine drip was employed for four to five minutes until complete skeletal muscle paralysis was evident and the resultant changes in intraocular tension recorded. 
Series IIT. The effect of a single intubating dose of succinylcholine immediately following complete skeletal muscle relaxation, as achieved with the 0.1 per cent succinylcholine drip was obseryed.

\section{ResUlts}

In Series I, 9 patients had an insignificant rise of 0 to $5 \mathrm{~mm}$. $\mathrm{Hg}, 6$ patients had a rise of 5 to $10 \mathrm{~mm}$. Hg while 3 rose more than $10 \mathrm{~mm}$. $\mathrm{Hg}$, with one as high as 17. The 9 patients with a rise of 5 or more are significant. In Series II, 6 patients out of $36 \mathrm{had}$ a significant rise of 5 to $10 \mathrm{~mm}$. $\mathrm{Hg}$, while $4 \mathrm{had}$ a fall of 5 to $10 \mathrm{~mm}$. Hg; $16 \mathrm{had}$ an insignificant rise of 0 to $5 \mathrm{~mm}$. $\mathrm{Hg}$, whyle 7 had a fall of 0 to $5 \mathrm{~mm}$. Hg. There were 3 patients without any change in tension. What is significant here is that 14 of the 36 patients had no change or a fall in oculart tension and that 16 had an insignificant rise. In Series III, 7 patients of 36 had a significant change in ocular tension, 3 having a rise and 4 a fall. What is most interesting is that 11 patients had no change in tension and 13 had an insignificant fall. Of the 3 patients with significant rises in ocular tension, it was felt that 2 had been inadequately depolarized with the 0.1 . per cent succinylcholine drip as fasiculation of the extremities occurred with the large dose: Therefore, of the 36 patients in Series III, only one had a significant rise in intraocular tension.

TABLE I

Siccinylcholine Effect on Ocular Tfision,

\begin{tabular}{|c|c|c|c|c|c|c|c|}
\hline \multirow[b]{2}{*}{ Succinylcholine } & \multicolumn{3}{|c|}{ Tension rise $(\mathrm{mm} . \mathrm{Hg})$} & \multirow{2}{*}{$\begin{array}{c}\text { No } \\
\text { change }\end{array}$} & \multicolumn{3}{|c|}{ Tension fall (mm. $\mathrm{Hg}$ ) } \\
\hline & $0-5$ & $5-10$ & $10+'$ & & $0-5$ & $5-10$ & $10+$ \\
\hline Series I & 9 & 6 & 3 & - & 1 & $\rightarrow$ & - \\
\hline Series II & 16 & 6 & 一 & 3 & 7 & 4 & - \\
\hline Series III & 5 & 2 & 1. & 11 & 13 & $2^{\prime}$ & 2 \\
\hline
\end{tabular}

TABLE 11

Intracocular ternsion in Association with ENDOTRACHEAL INTUHATION

\begin{tabular}{lccccc} 
& & Rise $\left(\mathrm{mm} . \mathrm{H}_{\mathrm{g}}\right)$ & \\
& $0-5$ & $5-10$ & $10+$ & 0 \\
\hline Without Topical & 8 & 5 & 10 & - \\
With Topical & 6 & 2 & 0 & 3 \\
\hline
\end{tabular}

In the course of studying the effect of succinylcholine on intraocular pressure, it was noted that endotracheal intubation immediately following the Series III study led to changes in ocular tension that frequently were far in excess of those produced by the succinylclfoline. From Table II it may be seen that of 23 cases, 8 had an insignificant rise, while 15 had significant rises and of these 10 were highly significant, one being as high as $30 \mathrm{~mm}$. $\mathrm{Hg}$ rise from normal. Further 
ihvestigation showed that if topical anaesthesia with 4 per cent Xylocaine was provided transtracheally 5 minutes prior to intubation the response to intubation was considerably altered. Of $\mathrm{H} 1$ cases, only $2 \mathrm{had}$ a rise of 5 to $10 \mathrm{~mm}$, 3 having no change, and 6 an insignificant rise. The rise in tension associated with intubation occurs rapidly and is not associated with a significant rise in venous pressure or arterial blood pressure. This.increase in tension tends to last longer than that associated with succinylcholine and, when the tension has returned to normal, it may again rise with movement of the endotracheal tuhe. Carrying out the transtracheal injection is also associated with a tise in tension, but it is nearly always insignificant and always of very short duration.

\section{Discussion}

From the limited series presented, it appears that a single intubating dose of succinylcholine which wears off in four to five minutes results in a significant rise ip ocular tension in about 50 per cent of individuals. This rise, however, is of short duration so that there is no contraindication to the use of suecinylcholine for intubating purposes as the rise in intraocular pressure of $5 \mathrm{~mm} . \mathrm{Hg}$ becomes significant only when the eye is open owing to the danger of vitreous being extruded. Where succinylcholine is used for intubation, the rise in ocular tension concomitant with muscle fasiculation and relaxation has long worm off before the surgeon is ready to open the eye.

From Series II, it can be seen that where depolarization of skeletal muscles is accomplished over four to five minutes with a 0.1 per cent succinylcholine drip so that fasiculation is not a feature of the depolarization, there is for all practical purposes no increase in intraocular tension. Where succinylcholine is desired for intubation and the surgeon is particularly anxious that there should be minimal changes in ocular tension, depolarization with a 0.1 per cent succinylcholine drip will provide the desired situation. If necessary, the succinylcholine drip may be maintained throughout the procedure as long as fasiculation is prevented.

Series III would seem to indicate that once a person is clinically depolarized the further administration of succirnylcholine in large doses does not lead to an increase in intraocular tension and in some cases may actually produce a fall.'

From Series II and III, which have gone further than previous studies in that, in one instance, complete depolarization òf skeletal muscle has been obtained through slow depolarization, and, in the other instance, a large amount of succinylcholine has been given to such a depolarized patient without increase in ocular tension, we may conclude that one of two things happened.

1. The extraocular muscles do, in fact, behave like skeletal muscle with the exception that larger amounts of circulating succinylcholine are required to produce equivalent ampunts of relaxation and that, as with skeletal muscle, if a large amount of succinylcholine is given quickly, fasiculations occur which cause a rise in intraocular pressure. If, however, fasiculation is prevented by slow depolarization, the rise in ocular tension is averted. The cases in which we had a significant rise in ocular tension were most probably due to too rapid depolarization as in some of these fasiculations were observed. 
2. The other possibility is that perhaps the muscles do go into a sustained contracture, but when the succinylcholine is given slowly there is time for compensatory mechanisms within the eye as, for example; redistribution of aqueous; and that once the muscle is in full sustained contracture further administration of succinylcholine is ineffectual. A method of study is to be carried out which will determine the significant factor.

As regards the increase in ocular tension following endotracheal intubation, it appears to be of greater significance than the rise in tension associated with succinylcholine. It seems to be of reflex origin, being minimized by adequate topical anaesthesia.

\section{SUMMMARY}

There appears to be no reason why succinylcholine cannot be used for intubation where deemed advantageous by the anaesthetist, for the rise in intraocular pressure has been dissipated long before the surgeon is ready to open the eye. Where a rise may be undesirable, slow depolarization is indicated. Indeed, where a rise in ocular tension is feared, it would seem that that associated with intubation in the absence of adequate topical anaesthesia or moderately deep general anaesthesia may be of far greater and prolonged extent than that produced by succinylcholine. It remains a fact, however, that a single large injection of succinylcholine should never be administered when the eye is open during intraocular surgery.

\section{RÉSUMÉ}

Chez 50 pour cent des individus, la succinylcholine à.dose unique, en vue de pratiquer une intubation, entraîne une atugmentation appréciable de la tension intra-oculaire. Toutefois, en deça de cinq minutes, la tension est revenue à ce quelle était, ce qui ne constitue pas úne contrindication à l'emploi de la succinylchaline pour l'intubation des cas de chirurgie intra-oculaire puisque la tension est normale au moment où l'on ouvre l'œil. Sî l'on emploie un goutte-à-goutte de succinyloholine à 0.1 pour cent pour dépolariser le malade de façon à éviter les fasciculations des extrémités, il n'existe plus, à toute fin pratique, d'augmentation de la tension oculaire. L'intubation endotrachéene s'accompagne également d'une élévation de tension intra-oculaire qui semble plus importante que celle qui suit l'administration de la succinylcholine. Cette augmentation de tension semble d'origine réflexe et elle serait diminuée pạr une anesthésie locale adéquate.

\section{ACKNOWLEDGMENTS}

We wish to thank Dr. A. B., Noble, Director of Anaesthesia, Royal Victoria Hospital, Montreal, for his helpful guidance, and Dr. A. P. H. McLean for his assistance in carrying out this study.

\section{REFERENCES}

1. Colle, J., Dukr-Eluer, P. M., \& Duke-Erder, W. S. Studies on the Intra-Ocular Pressure. Physiol. 71: I (1931). 
2. Drucker, A. P., SAdove, M. S., \& UNNA, K. R. Ophthalmic Studies of Curàre and Curarelike Drugs in Man. Am. J Ophth. 34: 543 (1951).

3. Lincoff, H. A.; Ellis, C. H.; DeVoe, A. G.; DeBeen, E. J.; Impaśtato, D. J.; Berg; S.; OnkIN, L.; \& MAGDA, H. The Effect of Succinylcholine on Intraocilar Pressure. Am. J. Ophth. 40: 501 (1955).

4. Macri, F. J., \& Gromes, P. A. The Effects of Succinylcholine on the Extraocular Striate Muscles and on the Intraocular Pressure. Am. J. Ophth. 44(2): 221 (1957).

5. Lincoff, H. A., Breinin, G. M., \& DeVoe, A. G. The Effect of Succinylcholine on the Extraocular Muscles. Am. J. Ophth. 43: 440 (1957).

6. Dillon, J. B.; Sabawala, P.; Taylor, D. B.; \& Gunter, R. Action of Succinylcholine on Extraocular Muscles and Intraocular Pressure. Anesthesiology 18: 44 (1957).

7. Dillon, J. B.; Sabawala, P.; Taylor, D. B.; \& Gunted, R. Depolarizing Neuromuscular Blocking Agents and Intraocular Pressure in vivo. Anesthesiology 18: 439 (1957).

8. Sugar, H. S. Factors in Normal Tension, in The Glaucomas, chap. v, p. 55. 2nd ed. 